\title{
Prevalence of alexithymia and its association with anxiety and depression in a sample of Greek chronic obstructive pulmonary disease (COPD) outpatients
}

\author{
Athanasios Tselebis*1, Epaminondas Kosmas², Dionisios Bratis ${ }^{1}$, Georgios Moussas ${ }^{1}$, Athanasios Karkanias \\ Ioannis Ilias ${ }^{3}$, Nikolaos Siafakas ${ }^{4}$, Alexandros Vgontzas ${ }^{5}$ and Nikolaos Tzanakis 4,6
}

\begin{abstract}
Background: Chronic obstructive pulmonary disease (COPD) is a major health problem, especially in adults over 40 years of age, and has a great social and economic impact. The psychological morbidity of COPD patients with regard to anxiety and depressive symptoms has been extensively studied in the past. However, few studies have investigated the prevalence of alexithymia in these patients, as well as its association with this comorbidity. Based on this fact, we studied the prevalence of alexithymia and its association with anxiety and depressive symptoms in COPD outpatients.

Methods: The present study included 167, randomly selected, outpatients diagnosed with COPD. Alexithymia, anxiety and depression were assessed using the Toronto Alexithymia Scale (TAS-20), Spielberger Trait Anxiety Inventory (STAI), and Beck Depression Inventory (BDI), respectively.

Results: The mean BDI score was 12.88 (SD: 7.7), mean STAI score 41.8 (SD: 11.0) and mean TAS-20 score 48.2 (SD: 11.5). No differences were observed between genders regarding age and alexithymia (t test $P>0.05$ ), while female patients presented higher depression and trait anxiety scores than males (t test $P<0.05$ ). Clinically significant levels of anxiety were present in $37.1 \%$ of men, and in $45.7 \%$ of women. The mean depression score was also higher than the corresponding mean score in the general population (one-sample t test $P<0.01$ ), while $27.7 \%$ and $30.5 \%$ of the sample presented mild and moderate to severe depression, respectively. Finally, a strong correlation was observed between alexithymia, depression and anxiety.

Conclusions: This study confirms the high prevalence of anxiety and depression symptoms in Greek outpatients with COPD. The prevalence of alexithymia in COPD patients, contrary to what has been observed in patients with other chronic respiratory diseases, seem to be lower. However, we observed a strong association between alexithymia, depression and anxiety levels. This observation suggests that alexithymia should be taken into consideration when drafting specific psychotherapeutic interventions for these patients.
\end{abstract}

\section{Background}

Chronic obstructive pulmonary disease (COPD) is one of the leading causes of mortality and morbidity worldwide. The disease is very common especially in smoker adults over 40 years of age and has a considerable social and economic impact [1]. In the USA it is the fourth highest

* Correspondence: atselebis@yahoo.gr

1 Psychiatric Department, Sotiria General Hospital of Chest Diseases, Athens, Greece

Full list of author information is available at the end of the article ranked condition leading to chronic morbidity and mortality and, according to the World Health Organization (WHO), it is expected to rank fifth in the year 2020 for burden of disease worldwide [2,3]. The disease is characterised by airflow obstruction that is not fully reversible; this airflow limitation is usually progressive and is associated with an abnormal inflammatory response of the lungs to noxious particles or gases, primarily caused by cigarette smoking [1]. 
With regard to Greece, studies from the 1980s pointed to this disease being a public health problem [4]. At the same time, COPD's effect on the psychological status of patients was recognised [5].

However, the relevant psychological status studies have mainly been focused on the prevalence of anxiety [6-10] and depression, which often appear together in these patients [11-15]. The prevalence of depression among outpatients with COPD is substantially greater than lifetime rates in the general population (ranging between $10 \%$ and $42 \%$ in the former, compared to approximately $5 \%$ in the latter). Correspondingly, the prevalence of anxiety varies from $10 \%$ to $19 \%$ [15], a percentage that is higher than the $15 \%$ that is reported in the general population $[16,17]$. Regarding patients who have recently recovered from an acute exacerbation of COPD, the prevalence of depression is even higher and ranges between $19.4 \%$ and $50 \%$ [15]. The same is true concerning anxiety, with the percentage ranges between $9.3 \%$ and $58 \%$ [15].

Both depression and anxiety are significantly associated with decreased functional status and worse health status when compared to those of patients without psychological symptoms, even after controlling for the effects of overall health status [13,17-19]. Higher predominance of depression and anxiety was observed in patients with COPD compared to patients that suffered from other chronic respiratory disorders, such as bronchial asthma and tuberculosis [17].

Alexithymia indicates 'lack of words for emotions' [20]. This term was first used in the 1970s, when Nemiah and Sifneos, evaluating psychiatric interviews of patients with classic psychosomatic ailments, found that most of these patients had great difficulty in describing their feelings verbally as well as limited capacity to fantasise [21]. Sifneos [20], in an effort to describe these symptoms under a coherent term coined the phrase alexithymia (loosely based on ancient Greek, from $\alpha \lambda \varepsilon \dot{\varepsilon} \varepsilon \varepsilon=$ deflect $+\theta u \mu$ เко = the emotional moiety of the soul); thus it literally implies a deflection of emotions. In general, subjects with alexithymia usually complain of somatic symptoms, regardless of their somatic ailment. At the same time they have great difficulty in recognising and describing their emotions [20-22]. Although the role of alexithymia and its association with levels of anxiety and depression has already been recognised in other respiratory diseases, such as bronchial asthma [23], few studies have investigated the possibility that alexithymia may also be prevalent in patients suffering from COPD [24-26].

Taking into account the high prevalence of anxiety and depression in patients with COPD [15], as well the reported associations among depression, anxiety, somatic symptoms and alexithymia [27], we studied the prevalence of alexithymia and its association with anxiety and depression in a sample of Greek COPD outpatients.

\section{Methods}

\section{Sample}

From the outpatients list of scheduled appointments at our hospital's clinics (among the largest respiratory disease hospitals in Europe) we selected those to be included in the study with randomisation using a Microsoft Excel (Microsoft, Redmond, WA, USA) algorithm (167 COPD outpatients). No patient refused to participate in the study. Subjects over the age of 80 years and patients diagnosed with other major somatic disorders (such as heart failure, myocardial infarction, cerebrovascular disease, cancer, or severe orthopaedic disorders) or major mental disorders (such as schizophrenia or sentimental disorder) were excluded from the study. The relevant information was obtained from the subjects' medical history and medical record. Age, gender, family status and education years were noted.

\section{Physical measures}

In order to determine the COPD severity of our sample, a spirometric evaluation before and after bronchodilation (200 $\mu \mathrm{g}$ salbutamol) was performed. We followed the Global Initiative for Chronic Obstructive Lung Disease (GOLD) diagnostic criteria, which classify COPD severity (in relation to forced expiratory volume in $1 \mathrm{~s}\left(\mathrm{FEV}_{1}\right)$ percentage of predicted) into four stages. Stage I (mild COPD): $\mathrm{FEV}_{1}>80 \%$ predicted; stage II (moderate COPD): $\mathrm{FEV}_{1} 50 \%$ to $80 \%$ predicted; stage III (severe COPD): $\mathrm{FEV}_{1} 30 \%$ to $50 \%$ predicted; and stage IV (very severe $\mathrm{COPD}$ ): $\mathrm{FEV}_{1}<30 \%$ predicted [3].

\section{Psychological measures}

Depression was assessed with the Beck Depression Inventory (BDI) [28], which includes 21 items graded from 0 to 3 . A high total score in the questionnaire corresponds to the presence of elevated depressive symptomatology $[16,17,23,29]$. The inventory has been standardised and used in Greek population. The inner coherence reliability $(\alpha=0.84)$ is high and the retest reliability ranges from 0.48 to 0.86 for clinical groups and 0.60 to 0.90 for non-clinical populations. Its validity in relation to an external criterion for depression (that is, a clinical diagnosis) is considered to be satisfactory [30].

Anxiety was assessed with the Spielberger State Trait Anxiety Inventory (STAI), a widely used anxiety rating scale [31]. It consists of 40 items, each graded from 1 to 4 . The scale differentiates anxiety into (a) anxiety caused by a specific condition (state subscale) and (b) anxiety as a more permanent characteristic of personality (trait subscale). The Greek validation of the trait subscale was used in our study, which is considered as having a high inner coherence reliability $(\alpha=0.89)$ and validity compared to clinical diagnosis $[32,33]$. 
Alexithymia was assessed with the Toronto Alexithymia Scale (TAS-20), which includes 20 items, graded from 1 to 5 . A high score $(>60)$ on the scale is consistent with increased presence of alexithymic characteristics [34]. The TAS-20 has been adapted into the Greek language and its reliability is considered to be satisfactory $(\alpha$ $=0.80)$ [35].

Before replying to the questionnaires used in this study, all the subjects were evaluated by two clinical psychologists in $60 \mathrm{~min}$ person-to-person sessions.

Statistical analysis was performed with analysis of variance (ANOVA) and Tukey's post hoc tests, Student $t$ test and stepwise multiple linear regression. Statistical significance was set at $P<0.05$ (corrected where applicable).

The hospital ethics committee approved the study and all participants provided written informed consent. No financial support was necessary.

\section{Results}

The sample included 132 men and 35 women. The mean age of the participants was $65.5 \pm 8.2$ (men: $65.4 \pm 8.1$ and women $65.7 \pm 8.5)$, while the mean $\mathrm{FEV}_{1}$ percentage of predicted was $41.5 \pm 18.7$ (Table 1 ). There were no differences between genders, regarding age, years of education, and $\mathrm{FEV}_{1}$ percentage of predicted (ANOVA $P>0.05$, Table 1$)$. The family status of the study's subjects $(77.7 \%$ were married, $4.6 \%$ were single, $7.7 \%$ were widowed and $10 \%$ were divorced) was not found to be associated with the studied parameters (one-way ANOVA $P>0.005$ ).

With regard to the severity of COPD according to the GOLD classification scheme, 10 patients had mild disease, 30 moderate disease, 75 severe disease and 52 were at a very severe stage of the disease.

Mean BDI score was $12.88 \pm 7.7$, mean STAI score was $41.8 \pm 11.0$ and mean TAS- 20 score was $48.2 \pm 11.5$. No differences were observed between genders, regarding age and alexithymia (TAS-20) (ANOVA $P>0.05$, Table 2 ), while female patients presented higher depression (BDI) and trait anxiety (STAI) scores than males (ANOVA $P<0.05$, Table 2 ).

Patients with COPD presented the same mean alexithymia score (48.2) as the general population's mean score (49.5) [35] (one-sample t test $P>0.05$ ). However, $12 \%$ of our sample presented with a score $>60$ (Table 3 ).

Men presented higher mean trait anxiety levels (ANOVA $P<0.01$ ) than the corresponding level (34.54) in the general Greek male population [32]. The same was also observed in women COPD patients compared to the mean corresponding score (37.47) in the general Greek population of women (one-sample t test $P<0.01$ ) [29]. Clinically significant levels of anxiety (score $\geq 44$ for men and $\geq 46$ for women) were present in $37.1 \%$ of men, and in $45.7 \%$ of women. The mean depression score was also higher than the corresponding mean score in the general population (5.86 one-sample t test $P<0.01$ ) [30], while
Table 1: Demographics and baseline characteristics.

\begin{tabular}{ll} 
Characteristic & Value \\
\hline Male/female & $132 / 35$ \\
\hline Age, years $( \pm$ SD) & \\
\hline Male & $65 \pm 8$ \\
\hline Female & $66 \pm 9$ \\
\hline Education, years $( \pm S D)$ & \\
\hline Male & $11 \pm 4$ \\
\hline Female & $11 \pm 5$ \\
\hline FEV ${ }_{1}$ (percentage of \\
predicted) $( \pm$ SD) \\
\hline Male
\end{tabular}

Severity (GOLD)

Mild/moderate/severe/very $\quad 10 / 30 / 75 / 52$

severe

$\mathrm{FEV}_{1}=$ forced expiratory volume in $1 \mathrm{~s} ; \mathrm{GOLD}=$ Global Initiative for Chronic Obstructive Lung Disease.

$24 \%$ and $35.3 \%$ of the sample presented mild (BDI score 10 to 14 ) and moderate to severe (BDI score $\geq 15$ ) depression, respectively (Table 3 ).

Mean $\mathrm{FEV}_{1}$ percentage of predicted, age and years of education showed no correlation with alexithymia, anxiety or depression score, while strong positive correlations were noted with alexithymia, anxiety and depression (Table 4).

To further assess factors that influence the depression score, we used stepwise multiple regression (Table 5). The trait anxiety score was responsible for $50.9 \%$ of variation in depression $\left(\mathrm{F} 1_{, 165}=170.74, P<0.001\right)$ and the alexithymia score for an additional $6.3 \%\left(\mathrm{~F}_{, 164}=24.06, P\right.$ $<0.01)$.

\section{Discussion}

The present study confirms the presence of a higher proportion of anxiety (approximately $37.1 \%$ for male and $45.7 \%$ for female) and depression (approximately $35.3 \%$ ) 
Table 2: Mean ( \pm SD) scores for Beck Depression Inventory (BDI), Spielberger Trait Anxiety Inventory (STAI) and Toronto Alexithymia Scale (TAS-20).

\begin{tabular}{ll}
\hline Category & Value \\
\hline Depression & \\
\hline Male $(\mathrm{N}=132)$ & $12.2 \pm 7.6$ \\
\hline Female $(\mathrm{N}=35)$ & $15.3 \pm 7.9$ \\
\hline Total $(\mathrm{N}=167)$ & $12.9 \pm 7.7$ \\
\hline
\end{tabular}

Anxiety

\begin{tabular}{lc}
\hline Male $(\mathrm{N}=132)$ & $41.1 \pm 10.4$ \\
\hline Female $(\mathrm{N}=35)$ & $44.7 \pm 10.6$ \\
\hline Total $(\mathrm{N}=167)$ & $41.8 \pm 10.5$ \\
\hline
\end{tabular}

Alexithymia

\begin{tabular}{ll}
\hline Male $(\mathrm{N}=132)$ & $48.0 \pm 11.2$ \\
\hline Female $(\mathrm{N}=35)$ & $49.2 \pm 12.8$ \\
\hline Total $(\mathrm{N}=167)$ & $48.2 \pm 11.2$
\end{tabular}

Females had higher trait anxiety and depression scores than males ( $t$ test $P<0.05$, for all comparisons).

in Greek outpatients with COPD than those in the general population. However, the lack of a control group may limit the generalisability of these results. The female population with COPD is differentiated from males by higher levels of anxiety and depressive symptoms. These findings are in accordance with previous studies that indicated a higher prevalence of overall anxiety and depressive symptoms among women with COPD $[15,36]$.
Independently of gender, there are many mechanisms that could be involved in this comorbidity. Patients with COPD have poor physical functioning, a condition which has been shown to be related to higher rate of psychological morbidity [36]. The high levels of anxiety and depressive symptoms are possibly the result of pressure from social factors, as well as from coping with daily living. Many of these patients have had to limit their daily activities due to their lung disease. They frequently have to change jobs or retire early. Their social interactions are also adversely affected because they cannot maintain pace with their peers [37]. In addition, patients with COPD soon realise that his/her disease is irreversible and progressive [14,37]. Furthermore, the hypoxic nature of the disease and dyspnoea may lead to increased distress $[36,37]$.

However, an impressive finding of our study was that anxiety and depression were not correlated with COPD severity (as determined by $\mathrm{FEV}_{1}$ percentage of predicted). In a previous study [38] it was reported that dyspnoea ratings were influenced by anxiety and depressive symptoms, whereas the physiological state (including $\mathrm{FEV}_{1}$ percentage of predicted) scarcely influenced the anxiety and depressive symptomatology. Although further studies are required in order to explain these findings, it is possible that patients construe disease seriousness subjectively, which contributes to the development of the levels of anxiety and depressive symptoms.

The prevalence of alexithymia in COPD patients, contrary to what has been observed in patients with other chronic respiratory diseases, seems to be lower. However, a positive correlation was observed between alexithymia, anxiety and depressive symptoms. Previous studies based on both clinical and healthy populations have reported a connection between depressive symptomatology and alexithymia, and it is well known that patients with depressive disorders are prone to experiencing alexithymic features [39,40]. Additionally, alexithymic features have been related to higher levels of anxiety [41]. Due to the limitations of our study, we cannot answer the question of whether alexithymia leads to depressive and anxiety symptoms or depression and anxiety symptoms lead to alexithymia.

Table 3: Prevalence of anxiety, alexithymia and depressive symptoms in relation to gender.

\begin{tabular}{llll}
\hline & Anxiety (STAI) & Alexithymia (TAS-20) & $\begin{array}{l}\text { Mild depression (BDI } \\
\text { 10-14) }\end{array}$ \\
\hline Male & $37.1 \%$ & $25 \%$ & $30.3 \%$ \\
depression (BDI 15) & $10.6 \%$ & $20 \%$ \\
\hline Female & $45.7 \%$ & $17.1 \%$ & $54.3 \%$ \\
\hline Total & $38.3 \%$ & $12 \%$ & $24 \%$ \\
\hline
\end{tabular}

BDI = Beck Depression Inventory; STAI = Spielberger Trait Anxiety Inventory; TAS-20 = Toronto Alexithymia Scale. 
Table 4: Correlation between forced expiratory volume in $1 \mathrm{~s}\left(\mathrm{FEV}_{1}\right)$ percentage of predicted, depression, anxiety and alexithymia.

\begin{tabular}{|c|c|c|c|c|}
\hline & & FEV1 percentage of predicted & BDI & STAI \\
\hline \multirow[t]{3}{*}{ BDI (depression) } & Pearson correlation & 0.085 & & \\
\hline & Significance (two-tailed) & 0.424 & & \\
\hline & $\mathrm{N}$ & 167 & & \\
\hline \multirow[t]{3}{*}{ STAI (anxiety) } & Pearson correlation & 0.068 & $0.805^{*}$ & \\
\hline & Significance (two-tailed) & 0.523 & 0.000 & \\
\hline & $\mathrm{N}$ & 167 & 167 & \\
\hline \multirow[t]{3}{*}{ TAS-20 (alexithymia) } & Pearson correlation & -0.026 & $0.510^{*}$ & $0.392 *$ \\
\hline & Significance (two-tailed) & 0.809 & 0.000 & 0.000 \\
\hline & $\mathrm{N}$ & 167 & 167 & 167 \\
\hline
\end{tabular}

Significant values in bold.

*Pearson correlation $P<0.01$.

$\mathrm{BDI}=$ Beck Depression Inventory; STAI = Spielberger Trait Anxiety Inventory; TAS-20 = Toronto Alexithymia Scale.

Compared with other psychosomatic and somatic diseases, such as bronchial asthma, the prevalence of alexithymia in COPD is lower. Furthermore, alexithymia may be related to recurrent very severe asthma exacerbations in asthmatics [42-44].

We did not study possible associations of COPD exacerbations with any of the other parameters studied. Thus, although we cannot support a similar hypothesis for COPD exacerbations, we believe that the correlations that were seen among alexithymia, depression and anxi- ety levels should be taken into consideration when drafting psychotherapeutic interventions (as a part of a pulmonary rehabilitation program) for these patients [45]. This is more pertinent in those patients with overall alexithymic characteristics (who often fail to recognise their underlying psychological malaise due to a lack of capacity for mental representation of emotions) [46,47]. These deficiencies may cause an inability to regulate emotions and affect and, therefore, may lead to increased somatisation and attenuated capacity to recognise the

Table 5: Stepwise multiple regression (only statistically significant variables are included)*.

\begin{tabular}{llllll}
\hline Variable & Multiple R & B & $\begin{array}{l}\text { Standard } \\
\text { error }\end{array}$ & $\boldsymbol{\beta}$ & Significance \\
\hline $\begin{array}{l}\text { STAI } \\
\text { (anxiety) }\end{array}$ & 0.713 & 0.445 & 0.041 & 0.606 & 10.908 \\
\hline $\begin{array}{l}\text { TAS-20 } \\
\text { (alexithymia) }\end{array}$ & 0.756 & 0.182 & 0.037 & 0.273 & 0.000 \\
\hline
\end{tabular}

Dependent variable: BDI (depression).

*The following variables were eliminated: age, gender, education years and $\mathrm{FEV}_{1}$ percentage of predicted.

$\mathrm{BDI}=$ Beck Depression Inventory; FEV 1 = forced expiratory volume in $1 \mathrm{~s} ; \mathrm{STAI}=$ Spielberger Trait Anxiety Inventory; TAS-20 = Toronto

Alexithymia Scale. 
underlying depressive symptoms or anxiety (and lack thereof of therapeutic intervention) [44,47]. Furthermore, subjects with high anxiety and depressive symptoms and concomitant alexithymia most probably have difficulty in verbally expressing their symptoms [22]. In alexithymia, by definition, the difficulty in expressing psychological symptoms as such leads to their expression as somatic (often atypical) symptoms [22]. The latter may distract clinicians and make them miss the psychological component that lies at the root of the problem. Given this, the possible presence of alexithymia should be taken into consideration when planning specialised psychotherapeutic interventions within respiratory rehabilitation programs.

Additionally, patients with severe depression and anxiety are less likely to be compliant to treatment plans and more likely to be hospitalised [48]. Therefore, comprehensive programs should incorporate individualised depression and anxiety management techniques.

Finally, this study does have some limitations. First is the lack of a control group; second, we did not study possible associations of COPD exacerbations with any of the other parameters studied. These limitations should be taken into consideration in further work.

\section{Conclusions}

This study confirms the high prevalence of anxiety and depression symptoms in Greek outpatients with COPD, a finding that is in accordance with relative studies worldwide. Additionally, our results are in agreement with other studies, which concluded that women have more psychological comorbidity [49-55].

In our study and in the most previous studies of patients with COPD, $\mathrm{FEV}_{1}$ percentage of predicted appeared to have an unfavourable effect, being a predictor of anxiety and depression in [50].

The prevalence of alexithymia in COPD patients, contrary to what has been observed in patients with other chronic respiratory diseases, seems to be lower. However, we observed a strong correlation between alexithymia, depression and anxiety levels, a finding suggesting that this comorbidity should be taken into consideration when drafting psychotherapeutic programs for these patients

\section{Competing interests}

The authors declare that they have no competing interests.

\section{Authors' contributions}

AT conceived the paper, designed the study, performed the psychological measures, collected data, carried out the statistical analysis and drafted the paper; EK performed the physical measures, carried out the statistical analysis and helped draft the paper; DB performed the psychological measures, collected data, gave suggestions for the concept of alexithymia and helped draft the paper; GM and AK helped draft the paper; II carried out the statistical analysis and helped draft the paper; NS and AV supervised the study; NT carried out the statistical analysis, helped draft the paper and supervised the study. All authors read and approved the final manuscript.

\section{Author Details}

1 Psychiatric Department, Sotiria General Hospital of Chest Diseases, Athens, Greece, ${ }^{2}$ Pulmonary Rehabilitation Centre, Sotiria General Hospital of Chest Diseases, Athens, Greece, ${ }^{3}$ Endocrine Department, Elena Venizelou Hospital, Athens, Greece, ${ }^{4}$ Department of Thoracic Medicine, University of Crete, Medical School, Heraklion, Greece, 5Psychiatric Department, University of Crete, Medical School, Heraklion, Greece and ${ }^{6}$ Departement of Social Medicine, Laboratory of Epidemiology, University of Crete, Medical School, Heraklion, Greece

Received: 30 December 2009 Accepted: 14 April 2010

Published: 14 April 2010

\section{References}

1. Nascimento OA, Camelier A, Rosa FW, Menezes AMB, Pérez-Padilla Jardim RJR, Latin American Project for the Investigation of Obstructive Lung Disease (PLATINO) Group: Chronic obstructive pulmonary disease is underdiagnosed and undertreated in São Paulo (Brazil). Results of the PLATINO Study. Braz J Med Biol Res 2007, 40:887-895.

2. Rabe KF, Hurd S, Anzueto A, Barnes PJ, Buist SA, Calverley P, Fukuchi Y, Jenkins C, Rodriguez-Roisin R, van Weel C, Zielinski J: Global strategy for the diagnosis, management, and prevention of chronic obstructive pulmonary disease: GOLD executive summary. Am J Respir Crit Care Med 2007, 176:527-528.

3. Global Strategy for the Diagnosis, Management and Prevention of COPD. Global Initiative for Chronic Obstructive Lung Disease (GOLD) 2007 [http://www.goldcopd.org]

4. Tzanakis N, Anagnostopoulou U, Filaditaki V, Christaki P, Siafakas N: Prevalence of COPD in Greece. Chest 2004, 125:892-900.

5. Kinsman RA, Fernandez E, Schocket M, Dirks JF, Covino NA: Multidimensional analysis of the symptoms of chronic bronchitis and emphysema. J Behav Med 1983, 6:339-357.

6. Yellowlees PM, Alpers JH, Bowden JJ, Bryant GD, Ruffin RE: Psychiatric morbidity in patients with chronic airflow obstruction. Med J Aust 1987, 146:305-307.

7. Wittchen HU, Zhao S, Kessler RC, Eaton WW: DSM III-R generalized anxiety disorder in the National Comorbidity Survey. Arch Gen Psychiatry 1994, 51:355-364.

8. Karajgi B, Rifkin A, Doddi S, Kolli R: The prevalence of anxiety disorders in patients with chronic obstructive pulmonary disease. Am J Psychiatry 1990, 147:200-201.

9. Zandbergen J, Bright M, Pols H, Fernandez I, de Loof C, Griez EJ: Higher lifetime prevalence of respiratory diseases in panic disorder? Am J Psychiatry 1991, 148:1583-1585.

10. Kvaal K, Macijauskiene J, Engedal K, Laake K: High prevalence of anxiety symptoms in hospitalized geriatric patients. Int J Geriatr Psychiatry 2001, 16:690-693.

11. Withers NJ, Rudkin ST, White RJ: Anxiety and depression in severe chronic obstructive pulmonary disease: the effects of pulmonary rehabilitation. J Cardiopulm Rehabil 1999, 19:362-365.

12. Kim HF, Kunik ME, Molinari VA, Hillman SL, Lalani S, Orengo CA, Petersen NJ, Nahas Z, Goodnight-White S: Functional impairment in COPD patients: the impact of anxiety and depression. Psychosomatics 2000, 41:465-471.

13. Yohannes AM, Baldwin RC, Connolly MJ: Depression and anxiety in elderly outpatients with chronic obstructive pulmonary disease: prevalence, and validation of the BASDEC screening questionnaire. Int J Geriatr Psychiatry 2000, 15:1090-1096.

14. Light RW, Merrill EJ, Despars JA, Gordon GH, Mutalipassi LR: Prevalence of depression and anxiety in patients with COPD: relationship to functional capacity. Chest 1985, 87:35-38.

15. Maurer J, Rebbapragada V, Borson S, Goldstein R, Kunik M, Yohannes AM, Hanania NA: Anxiety and Depression in COPD. Chest 2008, 134:43S-56S

16. Tselebis A, Gournas G, Tzitzanidou G, Panaghiotou A, llias I: Anxiety and depression in Greek nursing and medical personnel. Psychol Rep 2006, 99:93-96. 
17. Moussas G, Tselebis A, Karkanias A, Stamouli D, Ilias I, Bratis D, Vassila-Demi $\mathrm{K}$ : A comparative study of anxiety and depression in patients with bronchial asthma, chronic obstructive pulmonary disease and tuberculosis in a general hospital of chest diseases. Ann Gen Psychiatry 2008, 7:7

18. Felker B, Katon W, Hedrick SC, Rasmussen J, McKnight K, McDonnell MB, Finn SD: The association between depressive symptoms and health status in patients with chronic pulmonary disease. Gen Hosp Psychiatry 2001, 23:56-61.

19. Cleland JA, Lee AJ, Hall S: Associations of depression and anxiety with gender, age, health-related quality of life and symptoms in primary care COPD patients. Fam Pract 2007, 24:217-223

20. Sifneos PE: Short-Term Psychotherapy and Emotional Crisis Cambridge, MA, USA: Harvard University Press; 1972.

21. Nemiah JC, Sifneos PE: Affect and fantasy in patients with psychosomatic disorders. In Modern Trends in Psychosomatic Medicine Volume 2. Edited by: Hill OW. London, UK: Butterworths; 1970:26-34

22. Taylor GJ: Psychosomatic Medicine and Contemporary Psychoanalysis Madison, CT, USA: International Universities Press; 1987

23. Tselebis A, Moulou A, Ilias I, Bratis D: Depression, family support and alexithymia in patients with bronchial asthma. Ann Gen Psychiatry 2005, $4: 128$

24. Hynninen KM, Breitve MH, Wiborg AB, Pallesen $\mathrm{S}$, Nordhus $\mathrm{H}$ : Psychological characteristics of patients with chronic obstructive pulmonary disease: a review. J Psychosom Res 2005, 59:429-443.

25. Feiguine RJ, Johnson FA: Alexithymia and chronic respiratory disease. A review of current research. Psychother Psychosom 1985, 43:77-89.

26. Feiguine RJ, Jones NF: Alexithymia in chronic bronchitis/emphysema: personality characteristics and illness attitudes. Psychother Psychosom 1987, 47:95-100

27. Honcalampi K, Hintikka J, Laukkanen E, Lehtonen J, Viinamaki H: Alexithymia and depression. A prospective study of patients with major depressive disorder. Psychosomatics 2001, 42:229-234.

28. Beck AT, Steer RA: Manual for the Revised Beck Depression Inventory San Antonio, TX, USA: Psychological Corporation; 1987

29. Tselebis A, Moulou A, llias I: Burnout versus depression and sense of coherence: a study in Greek nursing staff. Nurs Health Sci 2001, 3:69-71.

30. Donias S, Demertzis I: Validation of the Beck Depression Inventory [in Greek]. In 10th Hellenic Congress of Neurology and Psychiatry: 1983; Thessaloniki Edited by: Varfis G. Thessaloniki, Greece: University Studio Press; 1983:486-492

31. Spielberger CD, Goruch RL, Lushene RE: The State-Trait Anxiety Inventory Palo Alto, CA, USA: Consulting Psychologists Press; 1970

32. Liakos A, Giannitsi S: Reliability and validity of the modified Greek version of the Spielberger State-Trait Anxiety Inventory. Encephalos 1984, 21:71-76.

33. Tselebis A, Papaleftheris E, Balis E, Theotoka I, Ilias I: Smoking related to anxiety and depression in Greek medical staff. Psychol Rep 2003, 92:529-532.

34. Bagby M, Taylor G, Parker J: The twenty-item Toronto Alexithymia Scale II. Convergent, discriminant and concurrent validity. J Psychosom Res 1994, 38:33-40.

35. Anagnostopoulou T, Kioseoglou G: The Toronto Alexithymia Scale - TAS 20 [in Modern Greek]. In Psychometric Tools in Greece Edited by: Stalikas A, Triliva S, Roussi P. Athens, Greece: Ellinika Grammata; 2002:100-101.

36. Laurin C, Lavoie KL, Bacon SL, Dupuis G, Lacoste G, Cartier A, Labrecque M: Sex differences in the prevalence of psychiatric disorders and psychological distress in patients with COPD. Chest 2007, 132:148-155.

37. Tselebis A, Moussas G, Bratis D: Psychological intervention in a COPD rehabilitation programme [in Modern Greek]. Pneumonologika Themata 2006:21-23.

38. Mishima M, Oku Y, Muro S, Hirai T, Chin K, Ohi M, Nakagawa M, Fujita M, Sato K, Shimada K, Yamaoka S, Oda Y, Asai N, Sagawa Y, Kuno K: Relationship between dyspnoea in daily life and psycho-physiologic state in patients with chronic obstructive pulmonary disease during long term domiciliary oxygen therapy. Intern Med 1996, 35:453-458.

39. Honkalampi K, Saarinen P, Hintikka J, Virtanen V, Viinamaki H: Factors associated with alexithymia in patients suffering from depression. Psychother Psychosom 1999, 68:270-275.

40. Honkalampi K, Hintikka J, Tanskanen A, Lehtonen J, Viinamaki H: Depression is strongly associated with alexithymia in the general population. J Psychosom Res 2000, 48:99-104.
41. Kim HW, Rim HD, Kim JH, Lee SJ: Alexithymia and stress response patterns among patients with depressive disorders in Korea. Psychiatry Invest 2009, 6:13-18.

42. Schier K: Affect regulation and self- and object representations in persons suffering from bronchial asthma. International Psychoanalytical Association. [http://www.ipa.org.uk/research/ schier.asp].

43. Leschinskaya B, Valeev R, Aftanas L, Kozlov V: Psychoimmunological facets of psychosomatic diseases: bronchial asthma vs. rheumatoid arthritis. Ann Gen Psychiatry 2006, 5(Suppl 1):S179.

44. Serrano J, Plaza V, Sureda B, de Pablo J, Picado C, Bardagi S, Lamela J, Sanchis J: Alexithymia: a relevant psychological variable in near-fatal asthma. Eur Respir J 2006, 28:296-302.

45. Kavoura P, Harikiopoulou M, Dumitru S, Theodorakopoulou E, Birba G, Lambrakis H, Bratis D, Tselebis A, Koulouris N, Alchanatis M, Roussos C, Kosmas E: Does pulmonary rehabilitation-induced improvement in BODE index correlate with improvements in anxiety and depression and quality of life? Chest Meet Abstr 2009, 136:52S-h.

46. Bratis D, Tselebis A, Sikaras C, Moulou A, Giotakis K, Zoumakis E, Ilias I: Alexithymia and its association with burnout, depression and family support among Greek nursing staff. Hum Res Health 2009, 7:72.

47. Mattila AK, Salminen JK, Nummi T, Joukamma M: Age is strongly associated with alexithymia in the general population. J Psychosom Res 2006, 61:629-635.

48. Mannino MD, Sidney B: The epidemiology and economics of chronic obstructive pulmonary disease. Proc Am Thoracic Soc 2007, 4:502-506.

49. Hill K, Geist R, Goldstein RS, Lacasse Y: Anxiety and depression in endstage COPD. Eur Respir J 2008, 31:667-677.

50. Funk GC, Kirchheiner K, Burghuber OC, Hartl S: BODE index versus GOLD classification for explaining anxious and depressive symptoms in patients with COPD - a cross-sectional study. Respir Res 2009, 10:1.

51. Carrasco-Garrido P, de Miguel-Díez J, Rejas-Gutierrez J, Martín-Centeno A, Gobartt-Vázquez E, Hernandez-Barrera V, de Miguel AG, Jimenez-Garcia R: Characteristics of chronic obstructive pulmonary disease in Spain from a gender perspective. BMC Pulm Med 2009, 9:2.

52. Gudmundsson G, Gislason T, Janson C, Lindberg E, Suppli UC, Brondum E, Nieminen MM, Aine T, Hallin R, Bakke P: Depression, anxiety and health status after hospitalisation for COPD: a multicentre study in the Nordic countries. Respir Med 2006, 100:87-93.

53. Di Marco F, Verga M, Reggente M, Maria Casanova F, Santus P, Blasi F, Allegra L, Centanni S: Anxiety and depression in COPD patients: the roles of gender and disease severity. Respir Med 2006, 100:1767-1774

54. Wagena EJ, Arrindell WA, Wouters EF, van Schayck CP: Are patients with COPD psychologically distressed? Eur Respir J 2005, 26:242-248.

55. Dahlen I, Janson C: Anxiety and depression are related to the outcome of emergency treatment in patients with obstructive pulmonary disease. Chest 2002, 122:1633-1637.

doi: $10.1186 / 1744-859 X-9-16$

Cite this article as: Tselebis et al., Prevalence of alexithymia and its association with anxiety and depression in a sample of Greek chronic obstructive pulmonary disease (COPD) outpatients Annals of General Psychiatry 2010, 9:16 